\title{
Construction of Hangzhou Silk Cognitive Evaluation System Based on the Grounded Theory
}

\author{
Xiangyang $\operatorname{Bian}^{1} \&$ Aijuan Cao ${ }^{1,2}$ \\ ${ }^{1}$ College of Fashion and Design, Donghua University, Shanghai, China \\ ${ }^{2}$ High Fashion Women Swear Institute, Hangzhou Vocational \& Technical College, Hangzhou, China \\ Correspondence: Xiangyang Bian, College of Fashion and Design, Donghua University, Shanghai, NO.1882, \\ West Yan-an Road, 200051, China. Tel: 86-21-6237-3978. E-mail: bianxy@dhu.edu.cn
}

\author{
Received: April 25, $2018 \quad$ Accepted: June 1, $2018 \quad$ Online Published: June 22, 2018 \\ doi:10.5539/ass.v14n7p92 URL: https://doi.org/10.5539/ass.v14n7p92
}

\begin{abstract}
The article adopts the grounded theory research method, where it takes "how people cognitive and evaluate Hangzhou Silk" as the research subject, and uses qualitative interviews that were obtained through interviews and investigations as data source. With the systematic analysis of the original data, this paper gradually extracts and summarizes the content dimension and evaluation results of consumers' cognition evaluation on Hangzhou silk using the quantitative analysis software NVivo 11.0. Finally, based on the eight dimensions of the above research, this study combs and analyzes the logical relationship between them, and constructs the cognition evaluation system of Hangzhou silk. The research conclusion enriches and expands the research scope in the field of silk cognition research.
\end{abstract}

Keywords: Hangzhou silk, grounded theory, cognitive evaluation, data coding

"People rode all the way to Hangzhou, half for the West Lake, half for silk." Hangzhou silk has a long history and is famous. It once created the glorious of Chinese silk. And it still plays a major role in the development of Chinese silk currently. In recent years, under the background of the "The Belt and Road" national strategy, the establishment of the international silk union in Hangzhou, and the increasing popularity of silk products, Hangzhou silk has once again attracted people's attention. However, in the actual survey, it is found that the evaluations that people had given to Hangzhou silk were always half praiseful and half contemptible. The reasons may include individual subjective factors and objective environmental factors. So in the consumer demand oriented market, it is of great significance to understand the people's cognitive dimension and build a scientific and effective evaluation system for promoting the overall image of Hangzhou silk and expanding the consumption of silk.

\section{Introduction of Grounded Theory}
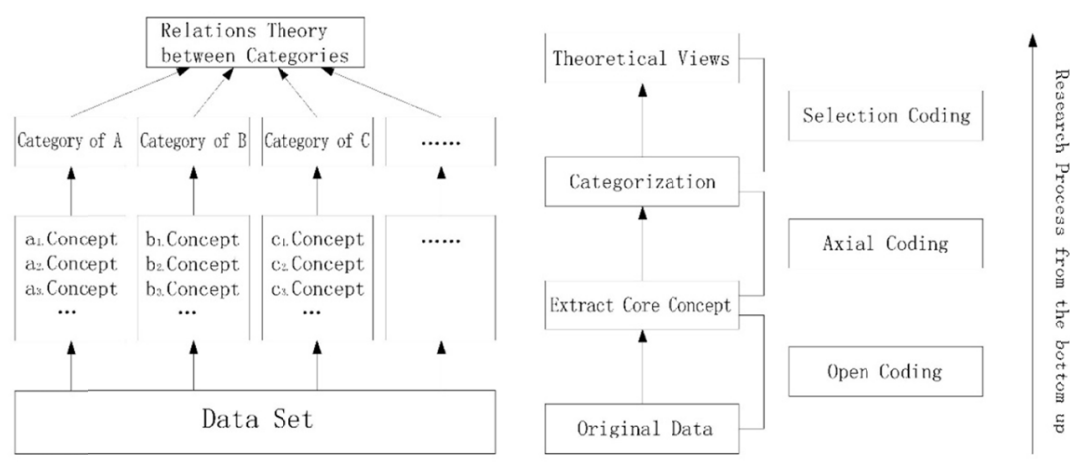

Figure 1. The Research Process of Grounded Theory

Grounded Theory is first proposed by Barney Glaser of Chicago University and Anselm Strauss of Columbia University in 1967 (Glaser \& Strauss, 1967, p. 271). It is a scientific and effective research method in the field of qualitative research. The core content of Grounded Theory is to start from the original data and extract the theory 
from phenomenon. The research process of the Grounded Theory is illustrated in Figure 1. Through the analysis of the original data, it finds out the core concepts that are related to goals and can reflect the essence of them. And then, the core concepts are analyzed, summarized and categorize one by one. Finally, it will analyze the relationships and functions among different categories, then build a result theory related to research objectives.

\section{Collect the Interview Data}

Qualitative survey is an important method to collect information in research process of Grounded Theory. In this study, the in-depth interview is divided into three processes. The first step is the small sample pre investigation stage: For the research topic, using "one-to-one" and "face-to-face" method, ten people were randomly selected to conduct an open interview, in order to revising the interview outline; The second step is the large-scale investigation stage: This study collects mass data by using these methods (such as "one-to-one", "face-to-face", "online" and "telephone" interviews); the third step is using "focus-groups discussion " research methods to get more original data in the large-scale research phase. The focus group consists of 4 to 8 people, where they take a thematic divergent discussion with each other in this third step. The "focus groups" are designed to enable interviewees to inspire each other and expand their thinking.

The interview revolves around the "Hangzhou silk in the eyes of the people", and revised the interview outline after the small sample interview. The subject is decomposed into four sub-questions with inner logic: (1) how to understand the word "Hangzhou silk"; (2) what do you think of "Hangzhou silk", and why do you think so? (3) what kind of "Hangzhou silk" do you expect? What about the "Hangzhou silk" in reality? The collection contains three part. The first is the demographic characteristics of the respondents (including gender, age, occupation, education level, and income). The second aspect is the interviewees' understanding of "Hangzhou silk". And the last aspect contains three points: the respondents' cognition of "Hangzhou silk", the results of cognitive evaluation, and the reasons for it.

The depth interview began in July 2015 and ended in February 2016, which lasted for eight months, spanning three seasons. The number of deep interviews is 216 , including 184 randomly selected ordinary consumers and 32 professionals engaged in production, design, marketing, management and research in the industry chain of Hangzhou silk. The purpose is to explore people's cognitive evaluation of "Hangzhou silk" from different perspectives. The description of the interview sample is detailed in Table 1.

Table 1. The Demographic Characteristics of the Surveyed Population

\begin{tabular}{|c|c|c|c|c|}
\hline Item & & Group & Sample & Effective Percentage (\%) \\
\hline \multirow{2}{*}{ Gender } & 1 & Male & 87 & 40.28 \\
\hline & 2 & Female & 129 & 59.72 \\
\hline \multirow{5}{*}{ Age } & 1 & Below 25 & 22 & 10.19 \\
\hline & 2 & Between 26 35 & 59 & 27.31 \\
\hline & 3 & Between 36 45 & 63 & 29.17 \\
\hline & 4 & Between $46 \sim 55$ & 51 & 23.61 \\
\hline & 5 & Above 55 & 21 & 9.72 \\
\hline \multirow{4}{*}{ The Highest Education } & 1 & College and below & 65 & 30.09 \\
\hline & 2 & Bachelor & 99 & 45.83 \\
\hline & 3 & Postgraduate and above & 52 & 24.07 \\
\hline & 1 & Less than $3500 \mathrm{RMB}$ & 31 & 14.35 \\
\hline \multirow{3}{*}{ Monthly Income } & 2 & Between 3501 6000 RMB & 51 & 23.61 \\
\hline & 3 & Between 6001 10000 RMB & 78 & 36.11 \\
\hline & 4 & Above $10000 \mathrm{RMB}$ & 56 & 25.93 \\
\hline \multirow{2}{*}{$\begin{array}{l}\text { Whether Silk Industry } \\
\text { Practitioners }\end{array}$} & 1 & ordinary Consumer & 184 & 85.19 \\
\hline & 2 & Silk industry practitioner & 32 & 14.81 \\
\hline \multirow{5}{*}{ Life Span in Hangzhou } & 1 & Less than one year & 24 & 11.11 \\
\hline & 2 & $1 \sim 3$ years & 35 & 16.20 \\
\hline & 3 & $4 \sim 10$ years & 57 & 26.39 \\
\hline & 4 & $11 \sim 20$ years & 68 & 31.48 \\
\hline & 5 & More than 20 years & 32 & 14.81 \\
\hline
\end{tabular}




\begin{tabular}{llccc}
\hline & 1 & face-to-face interview & 118 & 54.63 \\
Interview Method & 2 & Online interview & 54 & 25.00 \\
& 3 & telephone interview & 23 & 10.65 \\
& 4 & focus groups & 56 & 25.93 \\
\hline
\end{tabular}

Note: In the interview method column, there are 35 interviewers took part in one to one (face-to-face, online or telephone) interview, and also participated in the focus group.

\section{Data coding}

Data coding is the process of data extraction and analysis in qualitative research. It is divided into three steps: open coding, axial coding and selection coding.

\subsection{Open Coding}

Open coding is the process of discretizing and reorganizing the original data, and then conceptualizing each statement; its function is to identify the phenomena, define concepts, find categories and collect problems. In this process, the author label every sentence that can measure or evaluate Hangzhou silk, and then develops 728 initial concepts from the source material. However, these concepts overlap to a certain extent. According to the logical relationship among the initial concepts (such as causal relationship, membership, correlation, homogeneity, and so on),the concepts are summed up, classified and arranged, so as to further refine the 22 initial categories, such as quality (Ye, Li, \& Qian, 2008, pp. 662-666; Liu et al., 2007, pp. 49-52), price, design, emotional tendencies... etc. The open coding analysis example is shown in Table 2.

Table 2. An Example of Open Coding Analysis

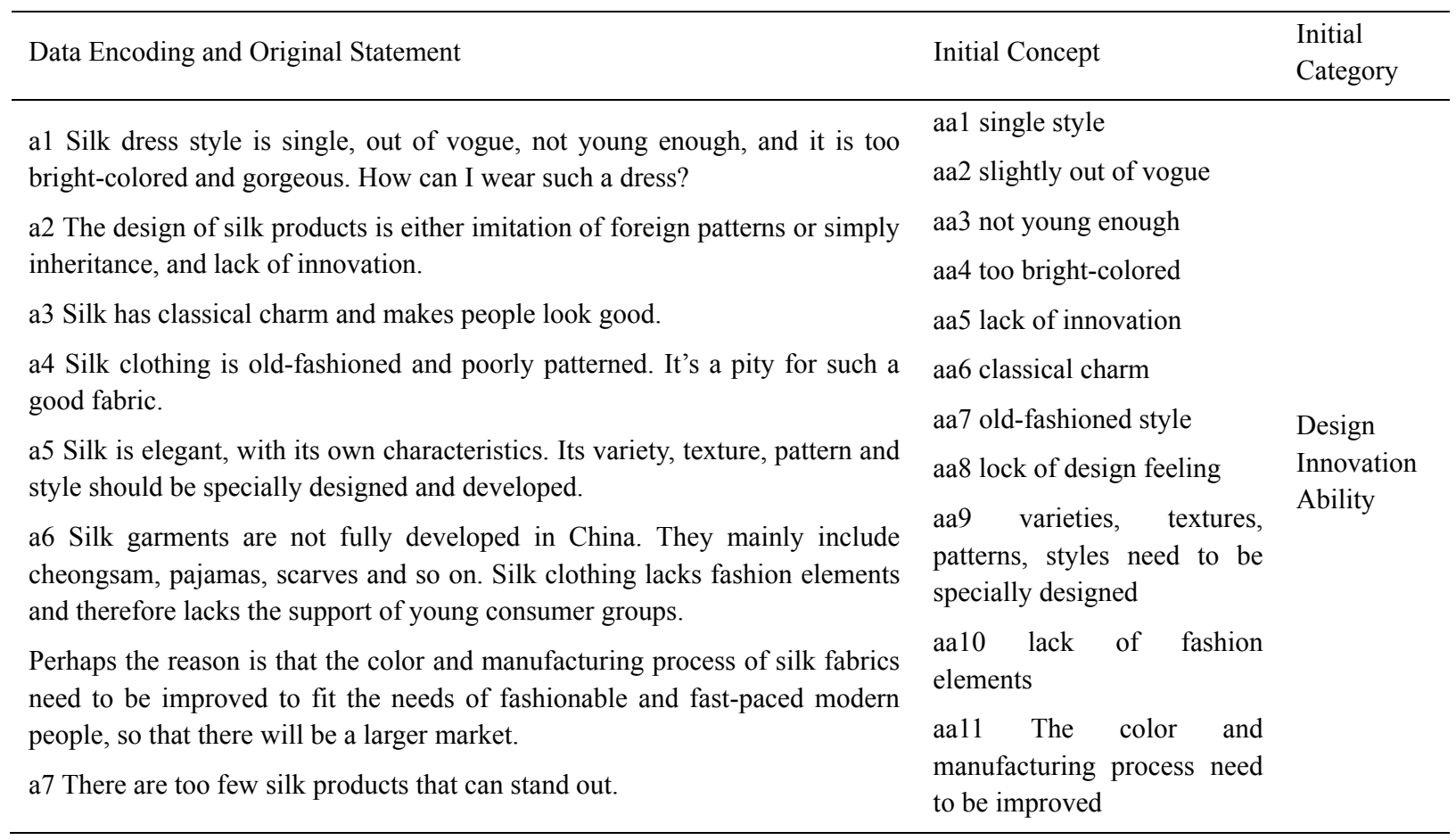

\subsection{Axial Coding}

The axial coding is the process of refining and distinguishing the initial category formed in the open coding. Its function is to identify and construct the interaction between the various categories, according to the research target (Uwe Flick, 2001, p. 248). Through depth analysis of the 22 initial categories formed by the open coding, this paper searches the relationship between each category, then and reclassifies those categories. Finally, eight main categories are formed: product knowledge, industry information, product performance, service performance, brand performance, social responsibility, cultural connotations (Huang et al., 2011, pp. 129-130; Zhang, 2011, pp. 50-53) and synthetic evaluation (see Table 3). 
Table 3. Axial Coding

\begin{tabular}{|c|c|c|c|}
\hline Main Category & Initial Category & Original Concept & Evaluation Index \\
\hline \multirow{4}{*}{$\begin{array}{l}\text { Product } \\
\text { Knowledge }\end{array}$} & Professional & performance characteristics: Comfort Property; Aesthetic & Professional \\
\hline & Knowledge & Property; Durability; Health Function; Convenience & Knowledge level \\
\hline & Experience & Purchase Experience; Application Experience; & Experience \\
\hline & Knowledge & Judging Ability & Knowledge level \\
\hline \multirow{6}{*}{$\begin{array}{l}\text { Industry } \\
\text { Information }\end{array}$} & Industry & Publicizing ; Promotion; Consumption Concept of Silk; & Impressive \\
\hline & Promotion & Advertisement & Effective \\
\hline & Direction of & & Information \\
\hline & Public Opinion & Positive Information; Negative Information & Processing Ability \\
\hline & Information & Paper Medium; Electronic Media; Public Praise; Other & Smooth Information \\
\hline & Channel & things & Channel \\
\hline \multirow{6}{*}{$\begin{array}{c}\text { Product } \\
\text { Performance }\end{array}$} & \multirow{3}{*}{ Properties } & Wearability (Comfort Property; Aesthetic Property; & \\
\hline & & Durability) & Practicality \\
\hline & & $\begin{array}{c}\text { Practicality (functional application; Service life; } \\
\text { Convenience) }\end{array}$ & Wearability \\
\hline & Quality & $\begin{array}{l}\text { model quality; Sewing Quality; dyeing Quality; packing } \\
\text { Quality }\end{array}$ & High Quality \\
\hline & Price & Performance- Price Ratio; Support Value Ability; Price & $\begin{array}{l}\text { Performance Price } \\
\quad \text { Ratio }\end{array}$ \\
\hline & Design & various Kinds; Costume Design; Fabric Design; Others & $\begin{array}{l}\text { Design and } \\
\text { Innovation Ability }\end{array}$ \\
\hline \multirow{3}{*}{$\begin{array}{l}\text { Brand } \\
\text { Performance }\end{array}$} & Brand Positioning & Many Product Brands; Brand Differentiating & Positioning Accuracy \\
\hline & Famous Brand & $\begin{array}{l}\text { Dujinsheng; CATHAYA; WENSLI; et al. } \\
\text { Identifiability; }\end{array}$ & Popularity \\
\hline & $\begin{array}{c}\text { Market } \\
\text { Performance }\end{array}$ & Market share; Growth Potentiality & Market Potential \\
\hline \multirow{4}{*}{$\begin{array}{l}\text { Service } \\
\text { Performance }\end{array}$} & $\begin{array}{l}\text { Service before } \\
\quad \text { Sale }\end{array}$ & Provide Professional Advice; Give Presentations & Specialty \\
\hline & Service in Sale & $\begin{array}{l}\text { Provide Instructions; Provide Accessories; meet the Unique } \\
\text { Needs; Impart Knowledge of Washing and Protection }\end{array}$ & $\begin{array}{l}\text { Considerate } \\
\text { Reliability }\end{array}$ \\
\hline & Service after Sale & virtual Communities; the Guarantee of After-sale Services & Service Attitude \\
\hline & $\begin{array}{c}\text { Staff and } \\
\text { Environment }\end{array}$ & $\begin{array}{l}\text { Shopping Environment; the Convenience of Purchase; } \\
\text { Staff Quality; Experience of Try-on }\end{array}$ & Store image \\
\hline \multirow{4}{*}{$\begin{array}{l}\text { Social } \\
\text { Responsibility }\end{array}$} & $\begin{array}{l}\text { Cultural } \\
\text { Inheritance }\end{array}$ & $\begin{array}{l}\text { Inheriting Silk Culture; Promote and Develop the Silk } \\
\text { Culture }\end{array}$ & \multirow{4}{*}{ Responsibility } \\
\hline & $\begin{array}{l}\text { Consumer } \\
\text { Protection }\end{array}$ & $\begin{array}{c}\text { Products and Services are Safe and Reliable; Treat Every } \\
\text { Consumer with Equality; Provide better Products and } \\
\text { Service; the Guarantee of After-sale Services }\end{array}$ & \\
\hline & $\begin{array}{l}\text { Environmental } \\
\text { Protection }\end{array}$ & $\begin{array}{l}\text { Reducing Pollution; Produce Environment-Friendly } \\
\text { Products; Support Environmental Action }\end{array}$ & \\
\hline & Charity & $\begin{array}{c}\text { Participate in Charity Activities; Help Tackle Social } \\
\text { Problem; Caring Vulnerable Group }\end{array}$ & \\
\hline \multirow{3}{*}{$\begin{array}{c}\text { Cultural } \\
\text { Connotation }\end{array}$} & $\begin{array}{l}\text { Historical } \\
\text { Attribute }\end{array}$ & Silk Industry Culture; Old Brand & $\begin{array}{l}\text { Long History } \\
\text { Richness }\end{array}$ \\
\hline & Cultural Attribute & National Culture: Hangzhou Culture & Nationality \\
\hline & Cuiturar Altrioute & Natronal culure, nangznou cuiture & Regionalism \\
\hline \multirow{2}{*}{$\begin{array}{l}\text { Synthetic } \\
\text { Evaluation }\end{array}$} & $\begin{array}{l}\text { Emotional } \\
\text { Inclination }\end{array}$ & Regional Tendency; Complex of Hangzhou Silk & $\begin{array}{l}\text { authentic; be } \\
\text { interested in; look } \\
\quad \text { forward to }\end{array}$ \\
\hline & $\begin{array}{l}\text { Rational } \\
\text { Cognition }\end{array}$ & Famous; High Status; Distinctive; Large-scale & $\begin{array}{l}\text { Popularity } \\
\text { Reputation }\end{array}$ \\
\hline
\end{tabular}




\subsection{Selection Coding}

Selective coding is to determine the core category, find the typical relationship between the core category and other main categories, in order to construct build the theoretical mode. That is to say, the role of selective coding is to connect all the other classes into a complete whole. According to the original data, the relationship between the main categories is analyzed. After selective coding, this study gets the core category, which is the "overall evaluation" of Hangzhou silk.

Taking the overall evaluation as the core, it controls 7 main categories and 22 initial categories. It can be summarized as follows: the knowledge of silk products and the information of Hangzhou silk industry are the inner individual factors affecting the overall evaluation of Hangzhou silk. The product performance, brand performance, service performance, social responsibility and cultural connotation of Hangzhou silk are the external environmental factors affecting the people's evaluation of the Hangzhou silk whole. Internal factors and external factors interact with each other and influence consumers' overall evaluation of Hangzhou silk. And the overall evaluation of Hangzhou silk by the people can be measured from two initial categories: emotional orientation and rational cognition.

\subsection{Theoretical Saturation Test}

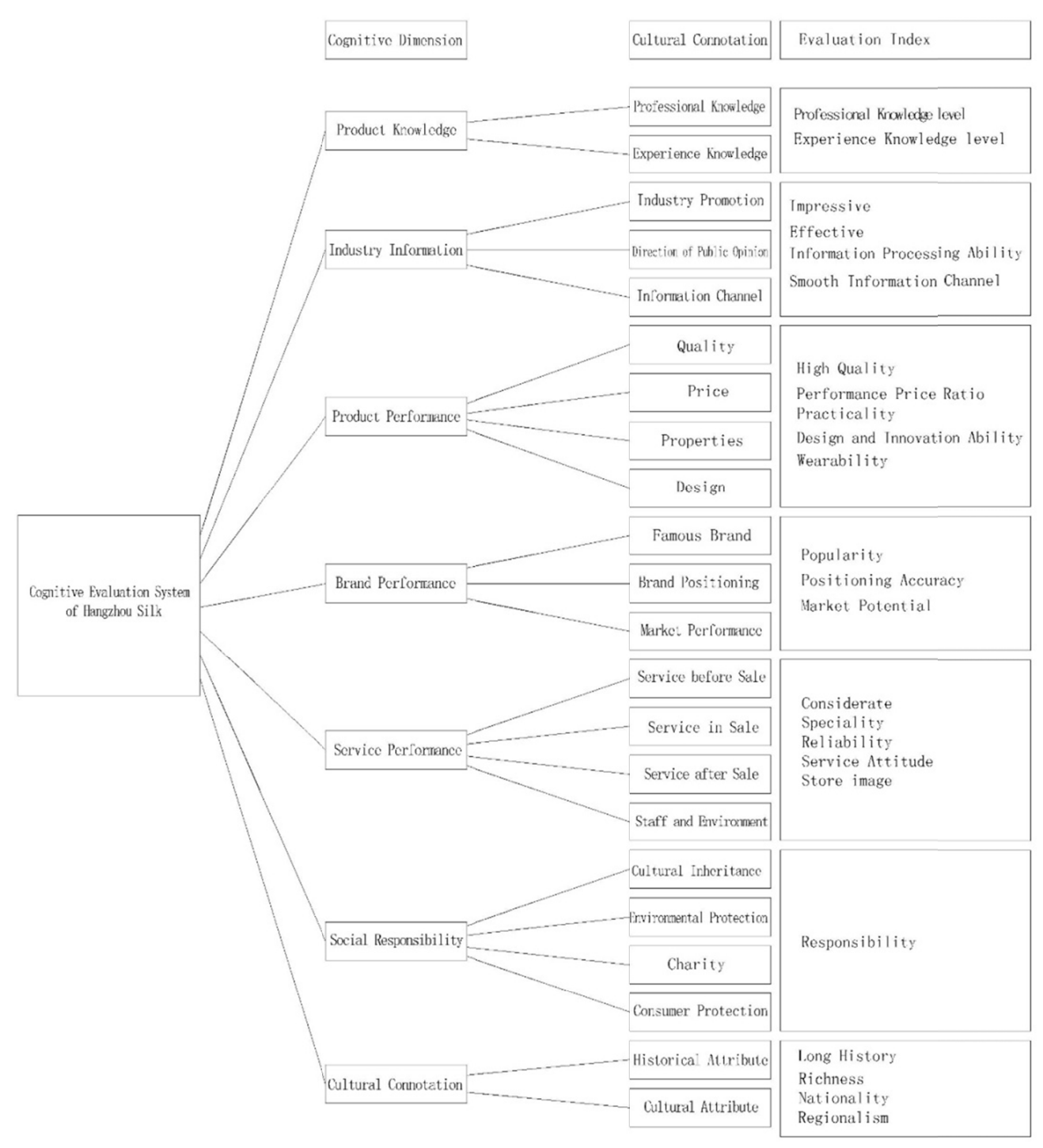

Figure 2. Cognitive Evaluation System of Hangzhou Silk

Theoretical saturation means that new categories cannot be obtained from extra data, which is also a criterion for stopping sampling. Through the analysis of the remaining $1 / 3$ of the original materials, there are no new categories in the conceptual model of Hangzhou silk cognitive evaluation system. The existing model system 
still includes the theoretical paradigms derived from new materials. And there is no new content in the eight main categories. So, by theoretical saturation test, there is no neglected elements or relationships between various elements. Based on these reasons, the Hangzhou silk cognition evaluation system shown in Figure 2 is relatively saturated.

According to Figure 2, there are seven dimensions of Hangzhou silk cognition evaluation. They are product performance, service performance, product knowledge, brand performance, industry information, social responsibility and cultural connotation. The evaluation indexes are quality, cost performance, practicality, taking and design innovation ability; service capacity and professionalism, service attitude, store image and reliability; professional knowledge level and experience richness; popularity, positioning and market potential; industry publicity and promotion, media guidance and information channels; inheritance of national culture, environmental protection, supporting for public welfare undertakings and safeguarding the rights of consumers; having a long history and deep culture, characteristics of national culture and origin culture (Xu \& Yuan, 2011, p. 9; Zhu, 1985, pp. 12-18).

\section{Research Conclusion}

Based on the grounded theory and the qualitative interviews of the public on Hangzhou silk cognition evaluation, eight main categories were extracted, including product performance, service performance, product knowledge, brand performance, industry information, social responsibility, cultural connotation and overall evaluation. Among them, taking the overall evaluation as the core, it controls 7 main categories and 22 initial categories, all of them constitute the Hangzhou silk cognition evaluation system. The logical relationship between the core category and the main categories implies the following:(1) The lack of knowledge in silk fabric products have significant negative impact on the overall evaluation of Hangzhou silk; (2) The negative information about Hangzhou silk negatively affects the public's influence on Hangzhou Silk. Overall evaluation; (3) The better the performance of Hangzhou silk products, the higher the public's overall evaluation of Hangzhou silk; (4) The better performance of Hangzhou silk services, the higher the overall evaluation of Hangzhou silk; (5) The better performance of Hangzhou silk brand The overall evaluation of Hangzhou Silk is higher; (6) The stronger the sense of corporate social responsibility in Hangzhou silk industry, the higher the overall evaluation of Hangzhou Silk is; (7) The deeper the cultural connotation of Hangzhou Silk Industry, the higher the public's overall evaluation of Hangzhou Silk is.

\section{Acknowledgments}

The authors would like to thank Donghua University and Hangzhou Vocational \& Technical. Meanwhile, thanks for the editor and the readers of Asian Social Science.

\section{References}

Fei, J. M. (2013). Hangzhou Silk Blue Book. Hangzhou: China Academy of Art Press.

Glaser, B, \& Strauss, A. (1967). The Discovery of Grounded Theory: Strategies for Qualitative Research. New York: Aldine Pub. Co.

Huang, X. M., Wang, Y. J., \& Song, X. J. (2011). Analysis of Psychological Cognition Factors of Consumers on Silk Gifts. Modern Silk Science \& Technology, 26(4), 129-130. https://doi.org/10.3969/j.issn.1674-8433.2011.04.004

Liu, X. F., Ji, X. F., \& Wang, J. (2007). Consumers' Perceptions of Silk Clothing Quality. Journal of Silk, (12), 49-52. https://doi.org/10.3969/j.issn.1001-7003.2007.12.018

Qian, X. P. (2001). Main Characteristics of Silk Culture. Journal of Dandong Teachers College, 23(1), 49-51.

Uwe Flick. (2001). An Introduction to Qualitative Research (Sun, J. translate). Chongqing: Chongqing University.

Xu, Z., \& Yuan, X. P. (2011). Hangzhou Silk History. Beijing: China Social Science Press.

Yao, M., Zhou, J. F., \& Huang, S. Z. (2003). Textile Material. Beijing: China Textile Press.

Ye, H. L., Li, X. H., \& Qian, L. X. (2008). Research on the Perceived Quality of Chinese Knitted Silk Garment. $\begin{array}{lllll}\text { Journal of Zhejiang } & \text { Sci-tech }\end{array}$ https://doi.org/10.3969/j.issn.1673-3851.2008.06.007

Yue, J., Zhang, X. X., \& Wang, G. H. (2014). Study on Application of Cognitive Behavior in Evaluating Tactility of Silk Fabrics. Journal of Silk, 51(9), 23-27. https://doi.org/10.3969/j.issn.1001-7003.2014.09.006

Zhang, J. H. (2011). Cultural metaphor and symbolic characteristics of silk. Journal of Silk, (9), 50-53. 
https://doi.org/10.3969/j.issn.1001-7003.2011.09.014

Zhu, X. Y. (1985). Zhejiang Silk History. Hangzhou: Zhejiang People's Publishing House.

\section{Copyrights}

Copyright for this article is retained by the author(s), with first publication rights granted to the journal.

This is an open-access article distributed under the terms and conditions of the Creative Commons Attribution license (http://creativecommons.org/licenses/by/4.0/). 